\title{
Parameters influencing the outcome after total disc replacement at the lumbosacral junction. Part 2: distraction and posterior translation lead to clinical failure after a mean follow-up of 5 years
}

\author{
Patrick Strube $\cdot$ Eike K. Hoff $\cdot$ Hendrik Schmidt • \\ Marcel Dreischarf • Antonius Rohlmann • \\ Michael Putzier
}

Received: 27 April 2013/Revised: 5 July 2013/Accepted: 12 August 2013/Published online: 23 August 2013 (c) Springer-Verlag Berlin Heidelberg 2013

\begin{abstract}
Purpose The aim of the second part of the study was to investigate the influence of parameters that lead to increased facet joint contact or capsule tensile forces (disc height, lordosis, and sagittal misalignment) on the clinical outcome after total disc replacement (TDR) at the lumbosacral junction.

Methods A total of 40 patients of a prospective cohort study who received TDR because of degenerative disc disease or osteochondrosis L5/S1 were invited to an additional follow-up for clinical (ODI and VAS for overall, back, and leg pain) and radiographic analysis (a change in disc height, lordosis, or sagittal vertebral misalignment compared with the preoperative state). Based on the final ODI, patients were retrospectively distributed into groups $N$ (normal: $<25 \%$ ) or $F$ (failure $\geq 25 \%$ ) for radiographic parameter comparison. A correlation analysis was performed between the clinical and radiological results.

Results A total of 34 patients were available at a mean follow-up of 59.5 months. Both groups $(N=24 ; F=10$ patients) presented a significant improvement in overall pain, back pain, and ODI over time. At the final follow-up, higher clinical scores correlated with a larger disc height, increased lordosis, and posterior translation of the superior
\end{abstract}

P. Strube and E. K. Hoff contributed equally to this work.

P. Strube $(\bowtie) \cdot$ E. K. Hoff - M. Putzier

Klinik für Orthopädie, Centrum für Muskuloskeletale Chirurgie,

Charité-Universitätsmedizin Berlin, Charitéplatz 1,

10117 Berlin, Germany

e-mail: Patrick.strube@charite.de

H. Schmidt · M. Dreischarf · A. Rohlmann

Julius Wolff Institut, Charité-Universitätsmedizin Berlin,

Augustenburger Platz 1, 13353 Berlin, Germany vertebra, which was also reflected by significant differences in these parameters in the group comparison.

Conclusions Parameters associated with increased facet joint capsule tensile forces lead to an inferior clinical outcome at mid-term follow-up. When performing TDR, we therefore suggest avoiding iatrogenic posterior translation and overdistraction (and consecutive lordosis).

Keywords Total disc replacement - Lumbar spine . Facet joint degeneration - Clinical outcome . Misalignment $\cdot$ Degenerative disc disease

\section{Introduction}

Motion-preserving technologies, such as lumbar total disc replacement (TDR), have been introduced as alternatives in the surgical treatment of low back pain resulting from degenerative disc disease (DDD) to avoid the negative side effects associated with vertebral fusion [1-10]. The clinical efficacy of TDR has been demonstrated in a variety of clinical class I and long-term studies [1, 5, 8, 10-13]. Nevertheless, several factors that negatively affect the clinical outcome after TDR have recently been elucidated [14-17]. A preoperatively existent high-grade facet joint degeneration (FJD) can especially lead to inferior clinical results; therefore, FJD was suggested as a contraindication for this procedure [18]. However, facet joint forces may increase after TDR followed by a de novo development or the progression of preoperatively existing initial FJD in a relevant percentage of patients (20-36\%) with a resulting inferior clinical outcome [19-23]. In a prospective study, Siepe et al. [23] found that FJD appeared more frequently at the index level compared with the adjacent levels and significantly more frequently at the lumbosacral junction 
compared with the levels above it. The latter may be caused by the unique facet joint configuration of L5/S1 or specific sagittal profile parameters [24] that theoretically result in higher facet joint shear stresses or contact forces [25]. Interestingly, patients with FJD progression after TDR present with inferior clinical results a few month postoperatively [23], which suggests that FJD itself may not be the only cause of pain or functional impairment. Several factors, such as malposition in the frontal plane, the grade of restoration of the disc height by segmental distraction, or the consecutive changes of the local sagittal curve with increased segmental lordosis, may affect facet joint forces after TDR [20, 25, 26]. In our probabilistic finite element model (FEM) analysis [27], we demonstrated that a segmental misalignment in the sagittal plane after TDR with an anterior or posterior shift of the superior vertebra leads to a significant increase in facet joint contact or capsule tensile forces. Although alterations in facet joint kinematics appear to be the crucial factor for clinical success after TDR (especially at the lumbosacral junction), these parameters have not been clinically investigated for their contributions to persistent postoperative pain, the progression or development of FJD, or a resulting functional impairment.

Therefore, we retrospectively analyzed the data of our patients treated with TDR at L5/S1 to identify sagittal geometry parameters (especially FEM-identified sagittal misalignment) responsible for clinical failure after TDR. We hypothesized that in patients who undergo TDR at the lumbosacral junction, an inferior clinical outcome is associated with a sagittal misalignment and/or an alteration of the local segmental curve or geometry.

\section{Patients and methods}

The present study is a retrospective analysis of patients included in a 1-year follow-up prospective cohort study that investigated the clinical and radiological outcomes after lumbar total disc replacement between 08/2005 and $12 / 2010$.

The inclusion criteria for the original study were painful (as proven by provocative discography) single-level DDD Pfirrmann and Resnick [28] grade $\geq$ III $^{\circ}$ and/or Modic [29] grade $\leq \mathrm{II}^{\circ}$ of segments L5/S1 or L4/5 (as found on MRI) after an unsuccessful period of conservative treatment for at least 6 months.

Patients were excluded from the study if they had degeneration of adjacent segments, as verified by MRI. Additionally, patients with FJD Fujiwara et al. [30] $\geq \mathrm{III}^{\circ}$ at any segment of the lumbar spine were excluded. A Fujiwara grade of $\mathrm{II}^{\circ}$ led to diagnostic facet joint infiltration, and patients were excluded from the original study in the case of a positive infiltration test result. Further exclusion criteria included additional degenerative findings; spinal deformities, spondylolisthesis Meyerding [31] $\geq \mathrm{I}^{\circ}$, or destructive processes; previous operations on the lumbar spine with the exception of sequestrectomy; patients on long-term medication with corticoids or non-steroidal antiinflammatory drugs (NSAIDs) or those with psychological distress syndrome or a somatization disorder of grade $\geq \mathrm{II}^{\circ}$ according to Gerbershagen et al. [32]; patients with osteoporosis, kidney or liver diseases, malignant tumors, or a BMI $>30 \mathrm{~kg} / \mathrm{m}^{2}$; an age of $>65$ years; pregnancy; or chronic nicotine, alcohol, or drug abuse.

The original clinical outcome parameters were assessed using a visual analog scale (VAS; performed preoperatively and at 1 week and 12 months postoperatively) for overall pain and back and leg pain. The Oswestry Disability Questionnaire Version 2 was used to assess function (ODI; performed preoperatively and 12 months postoperatively). Radiographs of the lumbar spine were acquired preoperatively and 1 week and 12 months postoperatively in the upright standing position to identify implant-associated failures. Major and minor complications were also recorded.

The study was approved by the local research ethics committee. Informed written consent was obtained from each patient.

All surgeries were conducted by the same senior surgeon (M.P.) and were performed via a pararectal retroperitoneal approach. Prior to implant placement, the intervertebral disc was resected, and the cartilaginous endplate was removed. The implant Maverick $^{\mathrm{TM}}$ A-MAV ${ }^{\mathrm{TM}}$, Medtronic, Memphis, USA) dimensions, angulations, and height were defined by fitting a test specimen/template according to the individual size and angle of the intervertebral space. The implant was press-fit anchored after distraction and resection of the posterior longitudinal ligament as described in the manual of the implant. Each patient was mobilized without an orthosis and given physiotherapy from the first postoperative day onward.

All patients with a TDR at L5/S1 included in the original study were invited to an additional radiological (plain upright standing lateral radiograph of the lumbar spine) and clinical examination (VAS for overall, back, and leg pain; ODI) for this study. All radiographic measurements and calculations were performed digitally employing functional $\mathrm{X}$-ray analysis (ACES GmbH, Esslingen, Germany) of radiographs (DICOM images) of the lumbar spine acquired in the lateral upright standing position preoperatively and at the final follow-up. This included digital sharpening, noise reduction, scaling, and correction of possible errors by segmental rotation and out of plane mismatch. Intraindividual comparisons of the parameters are based on a validated overlay correlation algorithm without the necessity of manual landmark placement or contour alignment, 
or other manual alignment between the images. The anterior-posterior translation (in millimeters) of the superior vertebra in relation to the arch of lordosis at the posterior wall of the inferior vertebra (APT; anterior, positive values; posterior, negative values; Fig. 1), the percentage of the vertebral translation in relation to the length of the inferior endplate (M) according to Meyerding [31], segmental lordosis (SL), and the anterior $(\mathrm{aDH})$, middle $(\mathrm{mDH})$, and posterior disc height $(\mathrm{pDH})$ of the surgically treated segment were the parameters measured. The mean disc height (meanDH) was calculated using $\mathrm{aDH}, \mathrm{mDH}$, and $\mathrm{pDH}$. The difference in the SL, aDH, $\mathrm{mDH}, \mathrm{pDH}$, meanDH, APT, and $M$ parameters between the preoperative and final follow-up states was calculated and used for new parameters referred to as "delta."
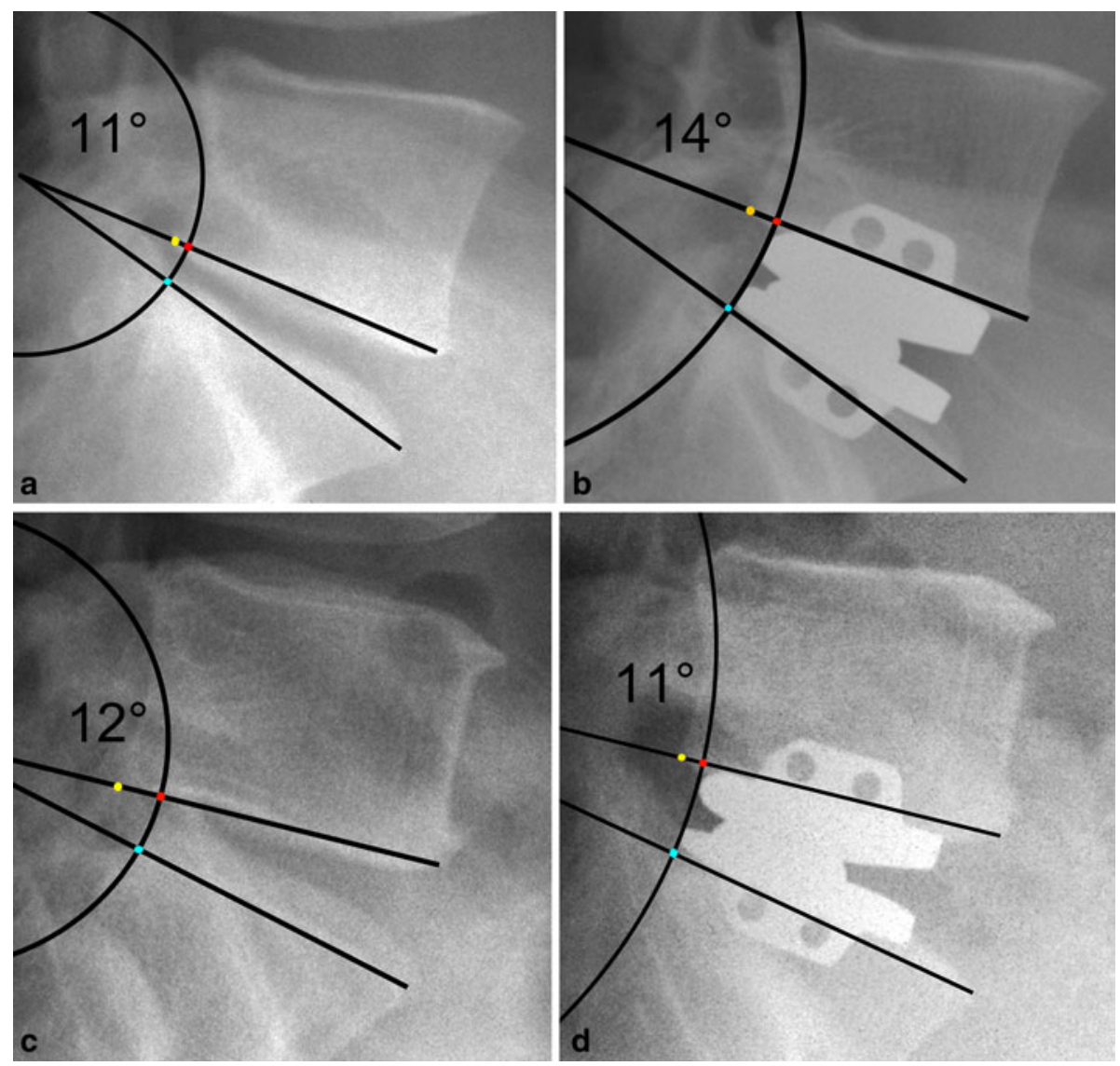

Fig. 1 Schematic illustration of an anterior-posterior vertebral translation (APT) after TDR corrected by distraction and the arch of lordosis. (This figure is an idealized visualization of the measurement parameters and does not meet the accuracy or validity of the digital picture analysis algorithm or error correction routines). In both cases (upper and lower row), TDR resulted in distraction that was visible via the decrease in the flexion of the arch from the left to the right column. Both patients presented with a preoperative (pseudo) retrolisthesis because of a larger inferior endplate of L5 compared with the superior endplate of S1. The blue dot indicates the crossing of the radius between the center of lordosis and the posterior superior
Based on the ODI at the final follow-up, patients were retrospectively assigned to two groups (F-functionally impaired, ODI $\geq 25 \%$; $N$-normal function ODI $<25 \%$ ). The cutoff of ODI $25 \%$ was based on the mean function of the "normal" population (ODI $10 \%$ ), the relevant clinical difference of ODI $15 \%$, and the acceptance of this cutoff between the patients with functional impairment and the "normal population" [33]. The radiological measurement parameters and clinical scores of the groups were compared, and a correlation analysis between the clinical scores and the radiologic measurement parameters was performed.

At the final follow-up, a facet infiltration test $(5 \mathrm{ml}$ at both sides; $0.5 \%$ Carbostesin $^{\mathrm{TM}}$; AstraZeneca, Germany) was performed to identify the facet joints as main pain

edge of S1 and the arch of lordosis. The red dot (crossing of the arch of lordosis and the transposed radius from S1 to the inferior endplate line of L5) serves as a marker for the measurement of the APT (distance between the posterior inferior edge of the L5 (yellow dot) and the red dot). The upper row shows a patient with iatrogenic posterior translation (and increase of lordosis from $11^{\circ}$ to $14^{\circ}$ ) at the b postoperative compared to the a preoperative state. This is indicated by an increase in the distance between the yellow and red dot, whereas in the lower row, an anterior translation and a slight decrease of lordosis from $12^{\circ}$ to $11^{\circ}$ is the result of TDR (c preoperative, d postoperative) 
generators. This test was performed for all patients in group F. In accordance with the literature [34, 35], the infiltration test was judged to be positive in the case of a VAS drop of at least $50 \%$ or $\geq 3 \mathrm{~cm} 1 \mathrm{~h}$ after injection.

The data from this study were analyzed using the PASW 18.0 statistics software (SPSS Inc. Chicago, USA) and Prism 5.0 (GraphPad Software Inc., San Diego, USA). Inter-group comparisons of postoperative ODI and VAS were conducted with a two-sided two-way analysis of variance for repeated measures (RM-ANOVA), and an intra-group comparison was performed with a two-sided, one-way RM-ANOVA. Post hoc tests with Bonferroni's correction were performed for all ANOVAs. The normality of the distribution was checked using the D'Agostino and Pearson omnibus normality test prior to applying parametrical testing. The correlation analysis between the parameters was based on Pearson's correlation coefficient, and the difference in the radiologic parameters between the groups was determined using a two-sided $t$ test. The significance level for all the statistical tests was set at $p<0.05$.

\section{Results}

Of the 40 patients included in the original study who were treated with a TDR at L5/S1, $34(85 \%)$ were available for the additional final evaluation at a mean of 59.5 (24-87) months after surgery. Four patients could not be contacted due to moving to an unknown address, and two patients were not willing to undergo a further clinical or radiological follow-up examination without specifying reasons. Of the 34 patients available for evaluation, 16 were female and 18 male. The mean age at surgery was 43.8 (minimum 29, maximum 60) years.

Two minor early postoperative complications were recorded during the primary study: one urinary tract infection that was treated with antibiotics and a persistent postoperative wound secretion that healed without specific treatment.

Ten patients were retrospectively assigned to group $\mathrm{F}$ because their final ODI was over $25 \%$ (minimum $32 \%$, maximum $56 \%$ ), whereas all other (24; ODI minimum $0 \%$, maximum $14 \%$ ) patients were assigned to group $\mathrm{N}$. The distributions of ODI and VAS scales over time and between groups are demonstrated in Fig. 2a-d.

In all patients of group $N$, the ODI, $\mathrm{VAS}_{\text {overall }}, \mathrm{VAS}_{\text {back }}$, and $\mathrm{VAS}_{\text {leg }}$ parameters significantly improved over followup (each ANOVA $p_{\text {time }}<0.001$; all parameters' post hoc tests preoperative vs. all others $p<0.001$ ). In group $F$, significant clinical improvements were observed for ODI (ANOVA $p_{\text {time }}=0.002$, post hoc tests preop vs. 12 months $p<0.01$ and vs. final follow-up $p<0.05$ ),
VAS ${ }_{\text {overall }}$, and VAS $S_{\text {back }}$ (each ANOVA $p_{\text {time }}<0.001$, post hoc tests for preoperative vs. 12 months and final followup $p<0.001)$, but not for $\mathrm{VAS}_{\text {leg }}\left(\right.$ ANOVA $\left.p_{\text {time }}=0.437\right)$ (Fig. 2a-d). A comparison between groups $N$ and $F$ showed better ODI scores (ANOVA $p_{\text {group }}<0.001$, $p_{\text {group }} \times$ time $\left.<0.001\right)$, VAS $_{\text {overall }}$ (ANOVA $p_{\text {group }}<0.001$, $p_{\text {group }} \times$ time $\left.=0.002\right), \quad$ and VAS $_{\text {back }}$ (ANOVA $p_{\text {group }}<0.001, \quad p_{\text {group }} \times$ time $\left.<0.001\right)$, but not $\mathrm{VAS}_{\text {leg }}$ (ANOVA $\left.p_{\text {group }}=0.181, p_{\text {group } \times \text { time }}=0.155\right)$ for group $N$. Post hoc comparisons are shown in Fig. $2 \mathrm{a}-\mathrm{d}$.

At the final follow-up, significant differences in the radiologic measurement parameters for (the change in) disc height, segmental translation, and lordosis were found between the groups (Table 1). The results of the correlation analysis between ODI/VAS scores and the radiographic measurement parameters at the final follow-up are reported in Table 2; Figs. 3, 4, 5. A significant Pearson's correlation was found between the final ODI and preoperative aDH $(r=-0.346, p=0.045)$; the final $\mathrm{VAS}_{\text {overall }}$ and preoperative $\mathrm{mDH}(r=0.481, p=0.004)$ and $\mathrm{pDH}(r=0.524$, $p=0.001)$; and the final $\mathrm{VAS}_{\mathrm{back}}$ and preoperative $\mathrm{pDH}$ $(r=0.506, p=0.002)$.

Facet infiltration at the index segment was evaluated in eight group $F$ patients. Two patients did not agree to an additional injection. The infiltration test was positive in five of these eight patients $(62.5 \%)$.

\section{Discussion}

In the second part of our study, we detected that (over)distraction with increased segmental lordosis and posterior translation of the superior vertebra led to clinical failure at the lumbosacral junction after TDR. To our knowledge, we are the first to observe that the iatrogenic changes that cause increased facet joint capsule tensile and shear forces are more likely to precipitate an inferior clinical outcome than those that create increased contact forces.

Similar to the results of Siepe et al. [22, 23], the patients with clinical failure reported pain during the early postoperative stage without apparent FJD at this time. The early and final clinical scores correlated with each other. Based on the results of the present study, these (early) negative results can be attributed to relatively small intraoperative changes of the segmental geometry, such as posterior translation or (over)distraction followed by increased lordosis. Our probabilistic FEM study identified that sagittal misalignment can cause both, increased facet joint capsule tensile forces in the case of iatrogenic posterior translation and increased compressive forces when iatrogenically shifting the superior vertebra anteriorly [27]. Although both situations would theoretically explain the 
Fig. 2 The image shows the results of a ODI, b VAS overall, $_{\text {, }}$ c $\mathrm{VAS}_{\text {back }}$, and $\mathbf{d} \mathrm{VAS}_{\text {leg }}$ for all patients in groups $N$ and $F$ over time. The whiskers indicate a single standard deviation.

"Preop." means preoperative, " $a$ " means significance at a level $p<0.001$, and " $b$ " indicates significance at a level $p<0.05$ in Bonferroni's post hoc tests between groups $N$ and $F$
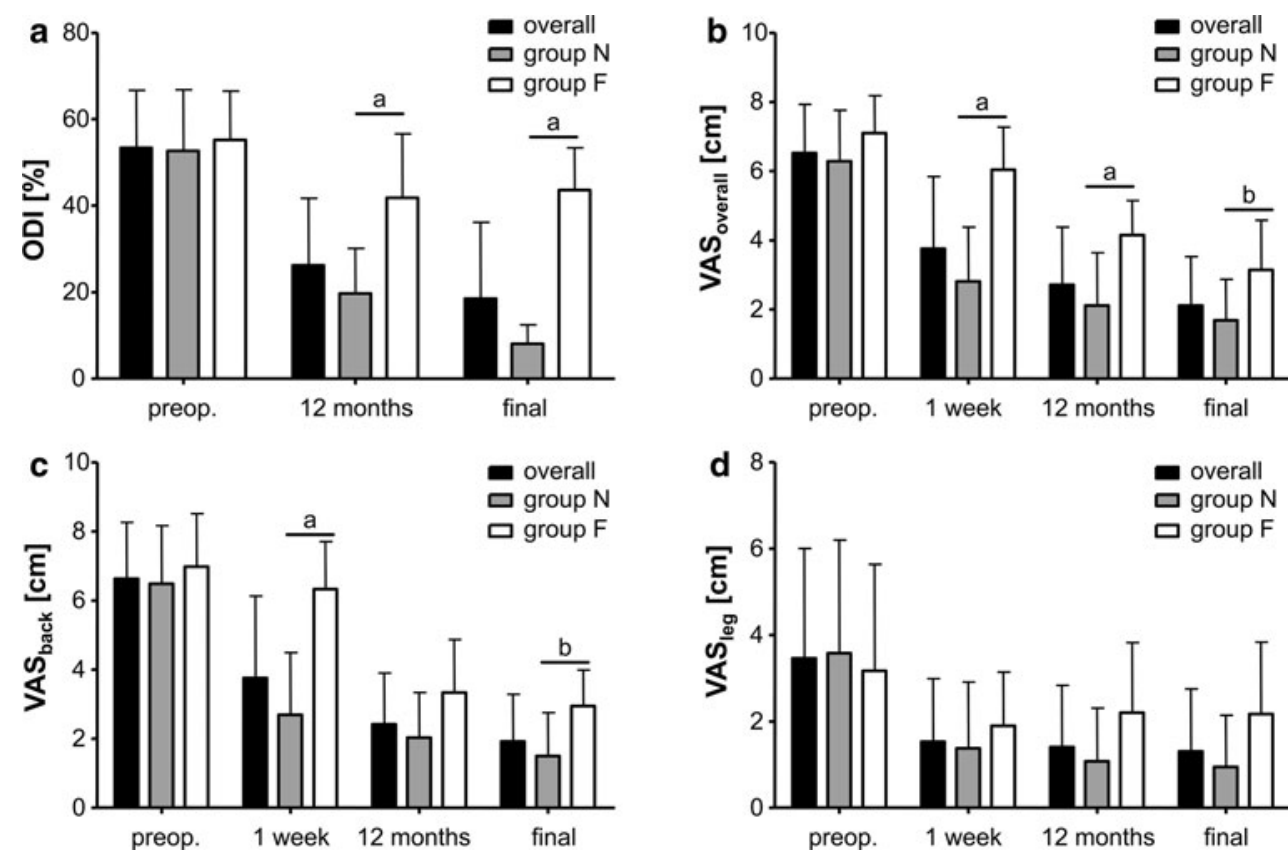
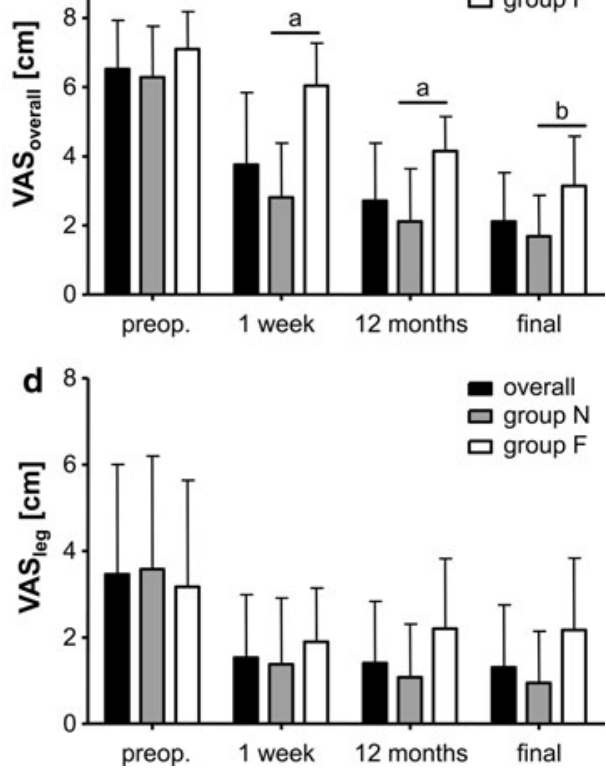

Table 1 Preoperative and final follow-up radiological measurement parameters (mean \pm SD)

\begin{tabular}{|c|c|c|c|c|}
\hline Parameter & $\begin{array}{l}\text { All patients } \\
(n=34)\end{array}$ & $\begin{array}{l}\text { Group } N \\
(n=24)\end{array}$ & $\begin{array}{l}\text { Group F } \\
(n=10)\end{array}$ & $p$-value* \\
\hline $\mathrm{SL}_{\text {preop }}\left({ }^{\circ}\right)$ & $15.09 \pm 5.25$ & $15.59 \pm 6.16$ & $13.90 \pm 1.34$ & 0.399 \\
\hline $\mathrm{SL}_{\text {final }}\left({ }^{\circ}\right)$ & $18.69 \pm 5.81$ & $16.73 \pm 4.80$ & $23.40 \pm 5.47$ & 0.004 \\
\hline delta SL $\left({ }^{\circ}\right)$ & $3.60 \pm 6.43$ & $-0.26 \pm 1.07$ & $9.50 \pm 5.26$ & 0.001 \\
\hline $\mathrm{aDH}_{\text {preop }}(\mathrm{mm})$ & $8.99 \pm 3.60$ & $9.80 \pm 3.54$ & $7.05 \pm 3.08$ & 0.035 \\
\hline $\mathrm{aDH}_{\text {final }}(\mathrm{mm})$ & $17.45 \pm 3.59$ & $16.42 \pm 3.63$ & $19.91 \pm 2.00$ & 0.001 \\
\hline delta aDH (mm) & $8.46 \pm 5.70$ & $6.62 \pm 5.05$ & $12.87 \pm 4.81$ & 0.003 \\
\hline $\mathrm{mDH}_{\text {preop }}(\mathrm{mm})$ & $5.78 \pm 2.22$ & $5.91 \pm 2.23$ & $5.47 \pm 2.27$ & 0.612 \\
\hline $\mathrm{mDH}_{\text {final }}(\mathrm{mm})$ & $13.12 \pm 4.25$ & $12.20 \pm 4.32$ & $15.33 \pm 3.30$ & 0.032 \\
\hline delta $\mathrm{mDH}(\mathrm{mm})$ & $7.34 \pm 4.58$ & $6.29 \pm 4.46$ & $9.86 \pm 4.01$ & 0.034 \\
\hline $\mathrm{pDH}_{\text {preop }}(\mathrm{mm})$ & $3.52 \pm 1.36$ & $3.50 \pm 1.38$ & $3.56 \pm 1.38$ & 0.922 \\
\hline $\mathrm{pDH}_{\text {final }}(\mathrm{mm})$ & $9.44 \pm 4.00$ & $8.80 \pm 4.09$ & $11.00 \pm 3.47$ & 0.126 \\
\hline delta pDH (mm) & $5.92 \pm 3.71$ & $5.29 \pm 3.65$ & $7.44 \pm 3.56$ & 0.129 \\
\hline meanDH $_{\text {preop }}(\mathrm{mm})$ & $6.10 \pm 2.00$ & $6.41 \pm 1.93$ & $5.36 \pm 2.06$ & 0.186 \\
\hline meanDH $_{\text {final }}(\mathrm{mm})$ & $13.33 \pm 3.76$ & $12.47 \pm 3.84$ & $15.41 \pm 2.72$ & 0.018 \\
\hline delta meanDH $(\mathrm{mm})$ & $7.24 \pm 4.54$ & $6.06 \pm 4.30$ & $10.06 \pm 3.97$ & 0.018 \\
\hline $\mathrm{APT}_{\text {preop }}(\mathrm{mm})$ & $-1.78 \pm 1.81$ & $-2.14 \pm 1.84$ & $-0.91 \pm 1.47$ & 0.052 \\
\hline $\mathrm{APT}_{\text {final }}(\mathrm{mm})$ & $-1.31 \pm 1.75$ & $-1.37 \pm 1.60$ & $-1.17 \pm 2.15$ & 0.794 \\
\hline delta APT (mm) & $0.47 \pm 1.39$ & $0.77 \pm 1.41$ & $-0.26 \pm 1.07$ & 0.031 \\
\hline $\mathrm{M}_{\text {preop }}(\%)$ & $5.85 \pm 5.58$ & $-6.88 \pm 5.63$ & $-3.40 \pm 4.86$ & 0.086 \\
\hline $\mathrm{M}_{\text {final }}(\%)$ & $6.38 \pm 5.97$ & $-5.92 \pm 5.47$ & $-7.50 \pm 7.22$ & 0.543 \\
\hline delta M (\%) & $0.53 \pm 4.97$ & $0.96 \pm 4.67$ & $-4.10 \pm 3.84$ & 0.004 \\
\hline
\end{tabular}

* $p$ values from two-sided $t$ test between groups $F$ and $N$

development of FJD in patients with TDR [19-23], we have proven that especially a posterior translation of the superior vertebra leads to clinical failure. As discussed, posterior translation leads to higher capsule tensile or shear forces. However, the combination of both overdistraction and an increase in segmental lordosis would theoretically aggravate the resulting facet joint capsule, but not the compressive joint forces. 
Table 2 Correlation results between clinical and radiological parameters at final follow-up

\begin{tabular}{|c|c|c|}
\hline \multirow[t]{2}{*}{ Clinical parameters } & \multicolumn{2}{|l|}{ Radiological/clinical parameters } \\
\hline & Positive correlations (Pearson's $r$ ) & $\begin{array}{l}\text { Negative correlations } \\
\text { (Pearson's } r \text { ) }\end{array}$ \\
\hline \multirow[t]{2}{*}{ VAS $_{\text {overall }}$} & Disc height: mDH (0.471)*; pDH (0.419); meanDH (0.427) & $\begin{array}{l}\text { Translation: delta APT } \\
(-0.468)^{*} ; \text { delta M } \\
(-0.449)^{*}\end{array}$ \\
\hline & Postop VAS Vverall $(0.629)^{*} ; 12$ months VAS $_{\text {overall }}(0.440)^{*}$ & \\
\hline \multirow[t]{3}{*}{$\mathrm{VAS}_{\text {back }}$} & Lordosis: delta SL $(0.415)$ & \\
\hline & $\begin{array}{l}\text { Disc height: aDH }(0.428) ; \mathrm{mDH}(0.602)^{*} ; \mathrm{pDH}(0.557)^{*} ; \text { meanDH } \\
(0.564)^{*} \text {; delta aDH }(0.448)^{*} \text {; delta } \mathrm{mDH}(0.415) \text {; delta } \mathrm{pDH} \\
(0.414) \text {; delta meanDH }(0.444)^{*}\end{array}$ & \\
\hline & Postop $\mathrm{VAS}_{\text {back }}(0.494)^{*} ; 12$ months $\mathrm{VAS}_{\text {back }}(0.454)^{*}$ & \\
\hline $\mathrm{VAS}_{\text {leg }}$ & Postop VAS $\mathrm{VAg}_{\text {leg }}(0.662)^{*} ; 12$ months $\mathrm{VAS}_{\text {leg }}(0.884)^{*}$ & \\
\hline \multirow[t]{2}{*}{ ODI } & Lordosis: SL $(0.439)^{*}$; delta SL $(0.538)^{*}$ & \multirow{2}{*}{$\begin{array}{l}\text { Translation: delta APT } \\
(-0.436) ; \text { delta M } \\
(-0.546)^{*}\end{array}$} \\
\hline & $\begin{array}{l}\text { Disc height: aDH }(0.495)^{*} ; \mathrm{mDH}(0.434) ; \mathrm{pDH}(0.386) \text {; meanDH } \\
(0.459)^{*} \text {; delta aDH }(0.531)^{*} ; \text { delta } \mathrm{mDH}(0.421) \text {; delta } \mathrm{pDH} \\
(0.360) \text {; delta meanDH }(0.463)^{*} ; 12 \text { months ODI }(0.722)\end{array}$ & \\
\hline
\end{tabular}

All demonstrated pairings of clinical and radiological or clinical parameters represent significant correlations $(p<0.05)$

$S L$ segmental lordosis, $p D H$ posterior disc height, $m D H$ middle disc height, $a D H$ anterior disc height, $m e a n D H$ mean disc height, $M$ vertebral translation according to Meyerding, $A P T$ lordosis-corrected anterior posterior vertebral trsanslation, delta represents the difference between the final follow-up and the preoperative state, Postop postoperative

* Indicates significance at $p<0.01$

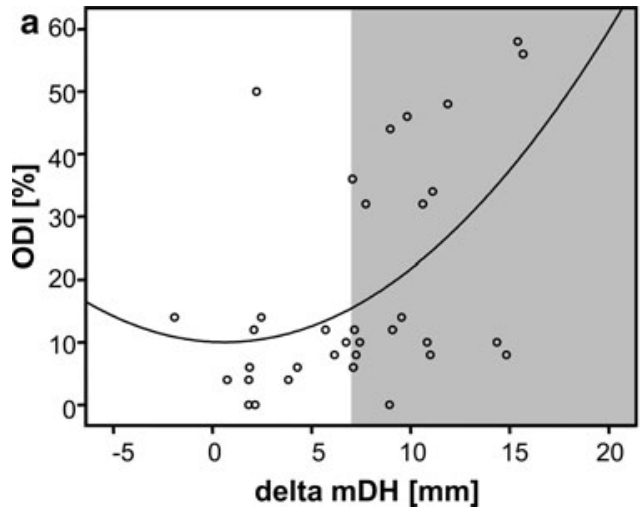

Fig. 3 The scatter-dot diagrams illustrate the exponential relationship between the TDR-caused distraction amounts (change of the intervertebral disc height from preoperative to postoperative state $=$ delta $\mathrm{mDH}$ ) and the clinical scores a ODI and b $\mathrm{VAS}_{\text {back }}$.

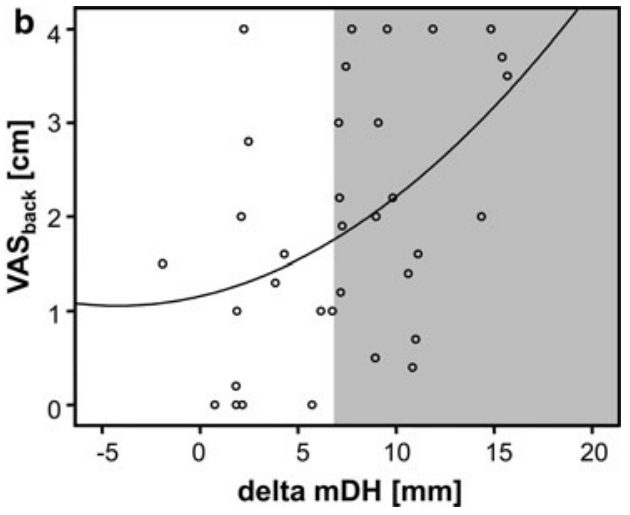

In both scores, approximately $80 \%$ of the clinical cases with an inferior outcome presented with a distraction of more than $6 \mathrm{~mm}$ (indicated by the gray area)
Fig. 4 The scatter-dot diagrams illustrate the exponential relationship between the lordosing effect of TDR from the preoperative to postoperative state (delta SL) and the clinical scores a ODI

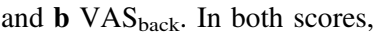
approximately $80 \%$ of the clinical cases with an inferior outcome presented with a lordosis increase of more than $5^{\circ}$ (indicated by the gray area)
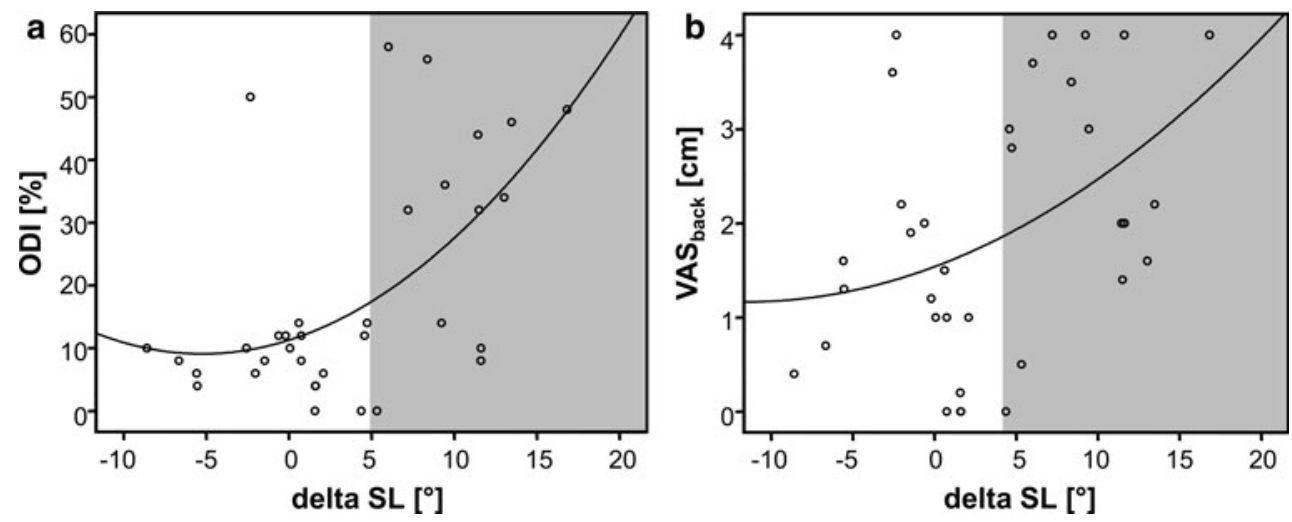
Fig. 5 The scatter-dot diagrams illustrate the exponential relationship between (upper row) the change in the anterior posterior vertebral translation (delta APT) or (lower row) the vertebral slippage according to Meyerding [31] (delta M) and the clinical scores a, c ODI and b, d VAS $_{\text {overall. In all scores, }}$ approximately $80 \%$ of the clinical cases with an inferior outcome presented with a posterior translation of less than $0 \mathrm{~mm} / 0 \%$ (indicated by the gray area)
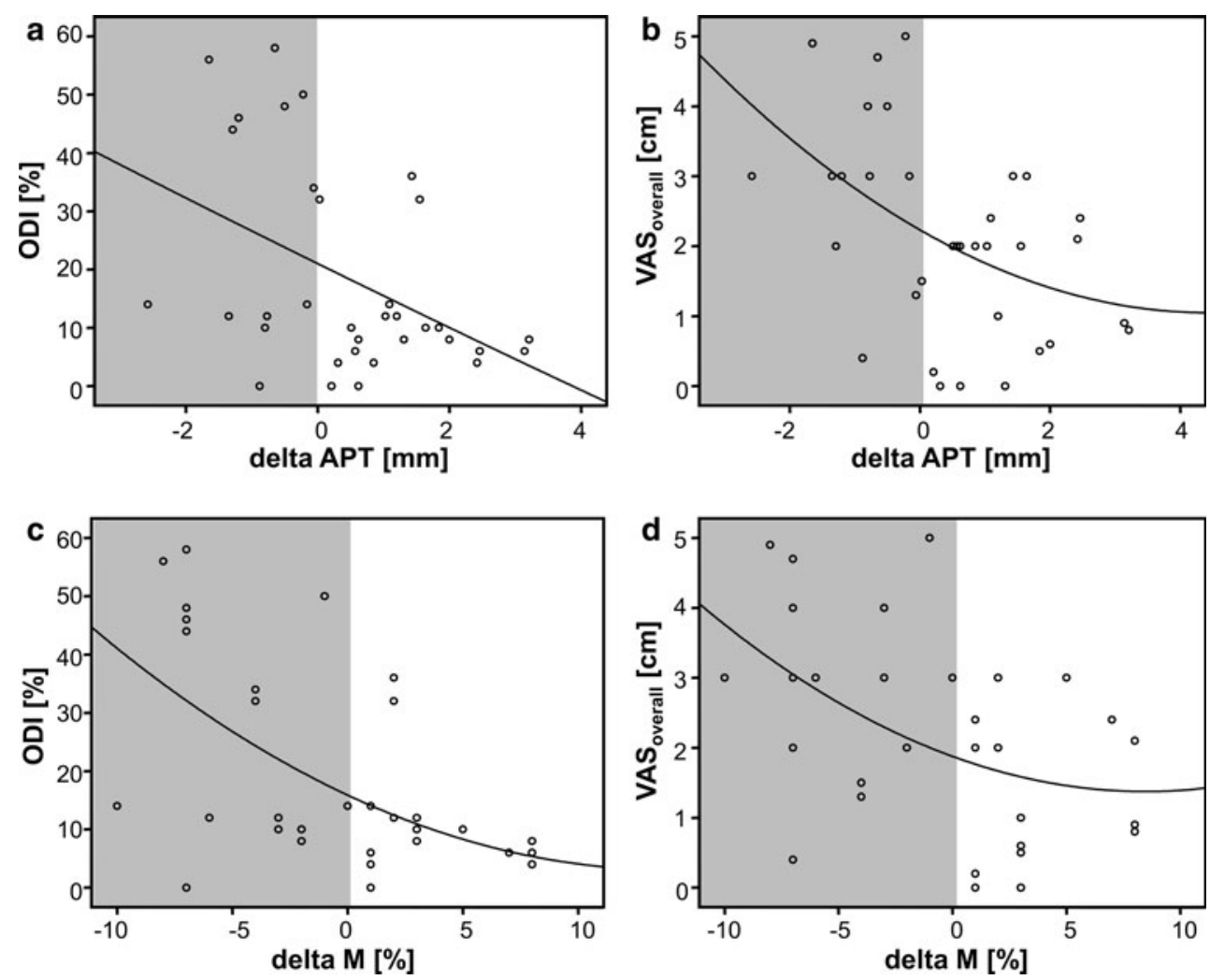

This finding is of special importance because these parameters are mutually dependent on each other regarding how they affect the facet joints. This mutual dependence has been previously demonstrated in cadaver studies: segmental iatrogenic distraction leads to increased lordosis followed by a reduced overlapping area of articulation and an increase in the space within the facet joints, similar to a subluxation [36, 37]. Rauschning [38] reported that subluxation of a joint leads to degeneration, which may explain the mechanism of FJD after TDR. All three parameters that correlated with an inferior clinical outcome in the present study lead to such a chronic subluxation. However, an iatrogenic anterolisthesis could likely neutralize the negative effect of segmental distraction on the tensile capsule forces. The number of our patients with anterior misalignment of the L5 vertebra $>2 \mathrm{~mm}$ was small $(N=4)$, and these patients presented with good to excellent clinical results at the early and mid-term postoperative follow-ups. These patients have potentially tolerated higher contact forces because the facet joints are geared to such loads. Studies with a longer follow-up should determine whether higher contact forces also result in FJD and inferior clinical outcomes.

With regard to the FEM and clinical results, it is important to intraoperatively avoid a misalignment of the implant in the sagittal plane. A posterior translation (especially at L5/S1) could result from different resistances of the two vertebrae against the anterior-posterior forces during preparation. The sacrum is stable and fixed in the pelvis, and therefore a posterior shift of the L5 vertebra during the cutting of the keel or the insertion of the implant could occur. Lee et al. [39] observed a malpositioning of the superior and inferior parts of the prosthesis in relation to the vertebral endplates caused by an angular mismatch between the prosthesis, the keel-cutting device, and the (distracted) lordosis of the segment during TDR (especially at L5/S1). Malpositioning could be another reason for anterior-posterior vertebral misalignment when employing a more constrained device similar to the one employed in the present study. Based on our results, the precise placement of the superior and inferior parts of the prosthesis is crucial for clinical success. A large misalignment could be detected radiographically and corrected by separate preparation of the superior or inferior component of the prosthesis during the operation. Nevertheless, although this could be clinically relevant, an intraoperative visualization of a 2- or 3-mm anterior-posterior misalignment appears to be at the margin of the measurement precision of fluoroscopy.

Distraction is usually necessary because the restoration of disc height after TDR is an important factor for a good clinical outcome [26, 40]. However, it is difficult for the surgeon to determine the ideal degree of correction of a degenerated disc, because the optimum amount is unknown 
and varies individually. No diagnostic tools can currently use preoperative radiologic images to estimate the needed physiologic disc height. Additionally, anatomic structures, such as muscles, ligaments and joint capsules, adapt to the degenerated status of the segment, but are not changed by TDR. TDR implants require a minimum intervertebral space. Therefore, the amount of distraction is larger in cases with a higher-grade DDD. The influence of preoperative disc height on the clinical outcome is controversial [41, 42]. However, the correlation between inferior postoperative clinical scores and a small preoperative disc height further strengthens the hypothesis that the postoperative adaptation of the soft tissue to distraction presents problems for motion preservation. Patients with highly degenerated segments and small disc heights could potentially experience larger benefits from fusion. In clinical practice, we therefore recommend avoiding segmental overdistraction because it could lead to the early clinical failure of TDR. Due to the correlation between these factors, an increased lordosis may be a good intraoperative indicator of excessive distraction.

Admittedly, our study is not without limitations. Due to the small number of patients, the results (especially the non-significant results) should be interpreted with caution. However, the radiologic factors that we found to be associated with inferior outcomes after TDR are supported by the calculations of our probabilistic FEM study and are consistent with several clinical observational studies [20, 25-27]. Additionally, significant results were obtained despite the use of relatively rigid statistical methods. Because shear stresses in the facet joints could not be measured and only $62.5 \%$ of the infiltration tests were positive, there is no direct proof of these forces being responsible for the inferior clinical results. Another limitation of our study was that we only used one implant type: a (semi)constrained ball-socket model. Further studies are needed to determine whether our findings can be transferred to different or unconstrained implants. An idealized spine model was employed in the probabilistic FEM study. This model did not take into consideration the segmental degeneration or adaptation due to this process, the morphology of the facet joints, or the influence of the varying soft tissue properties of the spinal motion segment. Therefore, the FEM results can only partially explain the outcome observed in the clinical aspect of the study.

In conclusion, our results indicate that overdistraction and sagittal misalignment-especially a posterior translation of the superior vertebra-are associated with clinical failure after TDR. We suggest using smaller implant sizes. We believe that the size of the implant should be geared more to the preoperative disc height than to an estimated physiological value. However, further studies with larger patient cohorts are necessary to determine optimal values.
Additionally, the introduction of an iatrogenic posterior translation has to be carefully avoided. Instrument development should focus on increasing the precision of implant positioning because issues relating to the intraoperative detection of small misalignments have not been solved thus far.

Acknowledgments The authors thank Marc Schürings for the help with the data collection and analysis.

Conflict of interest None.

\section{References}

1. Blumenthal S, McAfee PC, Guyer RD, Hochschuler SH, Geisler FH, Holt RT, Garcia R Jr, Regan JJ, Ohnmeiss DD (2005) A prospective, randomized, multicenter Food and Drug Administration investigational device exemptions study of lumbar total disc replacement with the CHARITE artificial disc versus lumbar fusion part I: evaluation of clinical outcomes. Spine (Phila Pa 1976) 30(14):1565-1575 (discussion E1387-1591)

2. Delamarter R, Zigler JE, Balderston RA, Cammisa FP, Goldstein JA, Spivak JM (2011) Prospective, randomized, multicenter Food and Drug Administration investigational device exemption study of the ProDisc-L total disc replacement compared with circumferential arthrodesis for the treatment of two-level lumbar degenerative disc disease: results at twenty-four months. J Bone Joint Surg Am 93(8):705-715

3. Gillet $P$ (2003) The fate of the adjacent motion segments after lumbar fusion. J Spinal Disord Tech 16(4):338-345

4. Gornet MF, Burkus JK, Dryer RF, Peloza JH (2011) Lumbar disc arthroplasty with MAVERICK disc versus stand-alone interbody fusion: a prospective, randomized, controlled, multicenter investigational device exemption trial. Spine (Phila Pa 1976) 36(25):E1600-E1611

5. Guyer RD, McAfee PC, Banco RJ, Bitan FD, Cappuccino A, Geisler FH, Hochschuler SH, Holt RT, Jenis LG, Majd ME, Regan JJ, Tromanhauser SG, Wong DC, Blumenthal SL (2009) Prospective, randomized, multicenter Food And Drug Administration investigational device exemption study of lumbar total disc replacement with the CHARITE artificial disc versus lumbar fusion: five-year follow-up. Spine J 9(5):374-386

6. Ha KY, Lee JS, Kim KW (2008) Degeneration of sacroiliac joint after instrumented lumbar or lumbosacral fusion: a prospective cohort study over five-year follow-up. Spine (Phila Pa 1976) 33(11):1192-1198

7. Kumar MN, Jacquot F, Hall H (2001) Long-term follow-up of functional outcomes and radiographic changes at adjacent levels following lumbar spine fusion for degenerative disc disease. Eur Spine J 10(4):309-313

8. McAfee PC, Cunningham B, Holsapple G, Adams K, Blumenthal S, Guyer RD, Dmietriev A, Maxwell JH, Regan JJ, Isaza J (2005) A prospective, randomized, multicenter Food and Drug Administration investigational device exemption study of lumbar total disc replacement with the CHARITE artificial disc versus lumbar fusion: part II: evaluation of radiographic outcomes and correlation of surgical technique accuracy with clinical outcomes. Spine (Phila Pa 1976) 30(14):1576-1583 (discussion E1388-1590)

9. Park P, Garton HJ, Gala VC, Hoff JT, McGillicuddy JE (2004) Adjacent segment disease after lumbar or lumbosacral fusion: review of the literature. Spine (Phila Pa 1976) 29(17):1938-1944 
10. Zigler J, Delamarter R, Spivak JM, Linovitz RJ, Danielson GO 3rd, Haider TT, Cammisa F, Zuchermann J, Balderston R, Kitchel S, Foley K, Watkins R, Bradford D, Yue J, Yuan H, Herkowitz H, Geiger D, Bendo J, Peppers T, Sachs B, Girardi F, Kropf M, Goldstein J (2007) Results of the prospective, randomized, multicenter Food and Drug Administration investigational device exemption study of the ProDisc-L total disc replacement versus circumferential fusion for the treatment of 1-level degenerative disc disease. Spine (Phila Pa 1976) 32(11):1155-1162 (discussion 1163)

11. David T (2007) Long-term results of one-level lumbar arthroplasty: minimum 10-year follow-up of the CHARITE artificial disc in 106 patients. Spine (Phila Pa 1976) 32(6):661-666

12. Lemaire JP, Carrier H, el Sariali H, Skalli W, Lavaste F (2005) Clinical and radiological outcomes with the Charite artificial disc: a 10-year minimum follow-up. J Spinal Disord Tech 18(4): 353-359

13. Tropiano P, Huang RC, Girardi FP, Cammisa FP Jr, Marnay T (2005) Lumbar total disc replacement. Seven to eleven-year follow-up. J Bone Joint Surg Am 87(3):490-496

14. Chin KR (2007) Epidemiology of indications and contraindications to total disc replacement in an academic practice. Spine $\mathbf{J}$ 7(4):392-398

15. Huang RC, Lim MR, Girardi FP, Cammisa FP Jr (2004) The prevalence of contraindications to total disc replacement in a cohort of lumbar surgical patients. Spine (Phila Pa 1976) 29(22):2538-2541

16. McAfee PC (2004) The indications for lumbar and cervical disc replacement. Spine J 4(6 Suppl):177S-181S

17. Wong DA, Annesser B, Birney T, Lamond R, Kumar A, Johnson S, Jatana S, Ghiselli G (2007) Incidence of contraindications to total disc arthroplasty: a retrospective review of 100 consecutive fusion patients with a specific analysis of facet arthrosis. Spine $\mathbf{J}$ $7(1): 5-11$

18. Le Huec JC, Basso Y, Aunoble S, Friesem T, Bruno MB (2005) Influence of facet and posterior muscle degeneration on clinical results of lumbar total disc replacement: two-year follow-up. J Spinal Disord Tech 18(3):219-223

19. Lemaire JP, Skalli W, Lavaste F, Templier A, Mendes F, Diop A, Sauty V, Laloux E (1997) Intervertebral disc prosthesis. Results and prospects for the year 2000. Clin Orthop Relat Res 337:64-76

20. Park CK, Ryu KS, Jee WH (2008) Degenerative changes of discs and facet joints in lumbar total disc replacement using ProDisc II: minimum two-year follow-up. Spine (Phila Pa 1976) 33(16): $1755-1761$

21. Shim CS, Lee SH, Shin HD, Kang HS, Choi WC, Jung B, Choi G, Ahn Y, Lee S, Lee HY (2007) CHARITE versus ProDisc: a comparative study of a minimum 3-year follow-up. Spine (Phila Pa 1976) 32(9):1012-1018

22. Siepe CJ, Korge A, Grochulla F, Mehren C, Mayer HM (2008) Analysis of post-operative pain patterns following total lumbar disc replacement: results from fluoroscopically guided spine infiltrations. Eur Spine J 17(1):44-56

23. Siepe CJ, Zelenkov P, Sauri-Barraza JC, Szeimies U, Grubinger T, Tepass A, Stabler A, Mayer MH (2010) The fate of facet joint and adjacent level disc degeneration following total lumbar disc replacement: a prospective clinical, X-ray, and magnetic resonance imaging investigation. Spine (Phila Pa 1976) 35(22): 1991-2003

24. Roussouly P, Gollogly S, Berthonnaud E, Dimnet J (2005) Classification of the normal variation in the sagittal alignment of the human lumbar spine and pelvis in the standing position. Spine (Phila Pa 1976) 30(3):346-353

25. Strube P, Hoff EK, Perka CF, Gross C, Putzier M (2012) Influence of the type of the sagittal profile on clinical results of lumbar total disc replacement after a mean follow-up of 39 months. J Spinal Disord Tech [Epub ahead of print]

26. Siepe CJ, Hitzl W, Meschede P, Sharma AK, Khattab MF, Mayer $\mathrm{MH}$ (2009) Interdependence between disc space height, range of motion and clinical outcome in total lumbar disc replacement. Spine (Phila Pa 1976) 34(9):904-916

27. Rohlmann A, Lauterborn S, Dreischarf M, Schmidt H, Putzier M, Strube P, Zander T (2013) Parameters influencing the outcome after total disc replacement at the lumbosacral junction. Part 1: misalignment of the vertebrae adjacent to a total disc replacement affects the facet joint and facet capsule forces in a probabilistic finite element analysis. Eur Spine J [Epub ahead of print]

28. Pfirrmann CW, Resnick D (2001) Schmorl nodes of the thoracic and lumbar spine: radiographic-pathologic study of prevalence, characterization, and correlation with degenerative changes of 1,650 spinal levels in 100 cadavers. Radiology 219(2):368-374

29. Modic MT, Steinberg PM, Ross JS, Masaryk TJ, Carter JR (1988) Degenerative disk disease: assessment of changes in vertebral body marrow with MR imaging. Radiology 166(1 Pt 1):193-199

30. Fujiwara A, Tamai K, Yamato M, An HS, Yoshida H, Saotome K, Kurihashi A (1999) The relationship between facet joint osteoarthritis and disc degeneration of the lumbar spine: an MRI study. Eur Spine J 8(5):396-401

31. Meyerding HW (1956) Spondylolisthesis; surgical fusion of lumbosacral portion of spinal column and interarticular facets; use of autogenous bone grafts for relief of disabling backache. J Int Coll Surg 26(5 Part 1):566-591

32. Gerbershagen HU, Lindena G, Korb J, Kramer S (2002) Healthrelated quality of life in patients with chronic pain. Schmerz (Berlin, Germany) 16(4):271-284

33. Fairbank JC, Couper J, Davies JB, O'Brien JP (1980) The Oswestry low back pain disability questionnaire. Physiotherapy 66(8):271-273

34. Hagg O, Fritzell P, Nordwall A (2003) The clinical importance of changes in outcome scores after treatment for chronic low back pain. Eur Spine J 12(1):12-20

35. Mannion AF, Junge A, Fairbank JC, Dvorak J, Grob D (2006) Development of a German version of the Oswestry Disability Index. Part 1: cross-cultural adaptation, reliability, and validity. Eur Spine J 15(1):55-65

36. Kafchitsas K, Kokkinakis M, Habermann B, Rauschmann M (2010) Effect of lumbar disc replacement on the height of the disc space and the geometry of the facet joints: a cadaver study. J Bone Joint Surg Br 92(4):595-601

37. Liu J, Ebraheim NA, Haman SP, Shafiq Q, Karkare N, Biyani A, Goel VK, Woldenberg L (2006) Effect of the increase in the height of lumbar disc space on facet joint articulation area in sagittal plane. Spine (Phila Pa 1976) 31(7):E198-E202

38. Rauschning W (1987) Normal and pathologic anatomy of the lumbar root canals. Spine (Phila Pa 1976) 12(10):1008-1019

39. Lee CS, Chung SS, Oh SK, You JW (2011) Significance of angular mismatch between vertebral endplate and prosthetic endplate in lumbar total disc replacement. J Spinal Disord Tech 24(3): 183-188

40. Tournier C, Aunoble S, Le Huec JC, Lemaire JP, Tropiano P, Lafage V, Skalli W (2007) Total disc arthroplasty: consequences for sagittal balance and lumbar spine movement. Eur Spine J 16(3):411-421

41. Bertagnoli R, Kumar S (2002) Indications for full prosthetic disc arthroplasty: a correlation of clinical outcome against a variety of indications. Eur Spine J 11(Suppl 2):S131-S136

42. Siepe CJ, Heider F, Haas E, Hitzl W, Szeimies U, Stabler A, Weiler C, Nerlich AG, Mayer MH (2012) Influence of lumbar intervertebral disc degeneration on the outcome of total lumbar disc replacement: a prospective clinical, histological, X-ray and MRI investigation. Eur Spine J 21(11):2287-2299 